\title{
Are UK doctors getting sufficient protective equipment against covid-19?
}

We have amended this feature article (BMJ 2020;369:m1297, doi:10.1136/bmj.m1297) in light of Public Health England's updated guidance on personal protective equipment published the same day as the feature was (see also BMJ 2020;369: m1391, doi:10.1136/bmj.m1391). 